\title{
Predictors of knowledge and use of long-lasting insecticidal nets for the prevention of malaria among the pregnant women in Pakistan
}

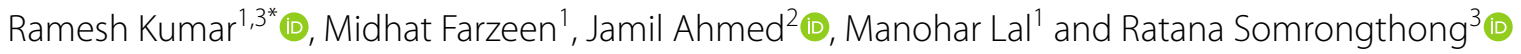

\begin{abstract}
Background: Malaria is endemic to Pakistan with high prevalence among pregnant women and linked with maternal anaemia, intrauterine growth retardation, preterm birth, and low birth weight. The use of long-lasting insecticidal nets (LLINs) is a proven and cost-effective intervention preventing malaria among pregnant women. The present study aimed to explore predictors of knowledge and use of LLINs among pregnant women in Pakistan.
\end{abstract}

Methods: This was part of a quasi-experimental study of 200 pregnant women conducted in a rural district of Sindh province in Pakistan. Data were collected using Malaria Indicator Survey questionnaires developed by Roll Back Malaria Partnership to end Malaria Monitoring and Evaluation Reference Group. Pregnant women and mothers with newborns of six months of age were interviewed in their homes.

Results: The age of the women was from 18 to 45, two thirds of the respondents (72.5\%) were uneducated and married (77\%). Majority (92\%) of the women had received antenatal care during pregnancy, and $29.5 \%$ women had received counseling on malaria during their antenatal care visits. Multiple linear regression showed that the type of latrine was the most significant $(\beta=0.285, p<0.001$ ) determinant of knowledge about malaria among pregnant women followed by the death of a newborn $(\beta=0.271, p<0.001)$. The use of mobile phone was the most significant $(\beta=0.247, p<0.001)$ predictor of usage of LLINs among pregnant women followed by the death of a newborn $(\beta=0.232, p<0.05)$.

Conclusions: Maternal education, type of latrine, use of mobile phone, malaria during previous pregnancy and newborn death were strong predictors of knowledge and use of LLINs in pregnant women in Pakistan. There is a need to scale-up programmes that aim to create awareness regarding malaria among pregnant women. Mobile phone technology can be used to implement awareness programmes focusing on malaria prevention among women.

Keywords: Malaria awareness/knowledge, Pregnancy, Predicator, Long-lasting insecticidal nets, Mosquito bite prevention, Factors and healthcare workers, Pakistan

\footnotetext{
*Correspondence: drramesh1978@gmail.com

${ }^{1}$ Health Services Academy, Ministry of National Health Services

Regulation and Coordination, Government of Pakistan, Islamabad, Pakistan

Full list of author information is available at the end of the article
}

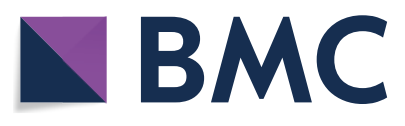

(c) The Author(s) 2021. Open Access This article is licensed under a Creative Commons Attribution 4.0 International License, which permits use, sharing, adaptation, distribution and reproduction in any medium or format, as long as you give appropriate credit to the original author(s) and the source, provide a link to the Creative Commons licence, and indicate if changes were made. The images or other third party material in this article are included in the article's Creative Commons licence, unless indicated otherwise in a credit line to the material. If material is not included in the article's Creative Commons licence and your intended use is not permitted by statutory regulation or exceeds the permitted use, you will need to obtain permission directly from the copyright holder. To view a copy of this licence, visit http://creativecommons.org/licenses/by/4.0/. The Creative Commons Public Domain Dedication waiver (http://creativeco mmons.org/publicdomain/zero/1.0/) applies to the data made available in this article, unless otherwise stated in a credit line to the data. 


\section{Background}

Malaria continues to be one of the major public health problems and sixth leading cause of death globally with 229 million cases annually, most in low-and-middleincome countries. Highest numbers of cases are reported in Africa followed by Eastern Mediterranean Region [1]. More than half of the population in the world is at substantial risk of malaria. An estimated $60 \%$ population currently lives in areas considered as moderately malaria endemic in Pakistan [1,2], with about 3,500,000 suspected and confirmed cases identified annually. Plasmodium falciparum represents $15 \%$ of cases, and cumulative annual parasitic index (total number of positive slides for malaria in a year $\times 1000 /$ Total population) in Pakistan is around 1.8 [3]. Multiple factors cause high transmission of malaria in Pakistan, including migration of people, low immunity, climatic changes variability, socio-economic conditions, weak health system, resource constraints, illiteracy, and suboptimal use of long-lasting insecticidal nets (LLINs) [3].

Pregnant women and children are at an increased risk of severe illness and deaths due to malaria [4]. Malaria is known to cause a high level of morbidity and mortality in both mothers and their newborn in low-and-middleincome countries [5]. Pregnant women may also have asymptomatic parasitaemia, and their newborns can also be exposed through placenta in malaria endemic zones [6]. Low birth weight, abortion, and miscarriage are serious health problems due to gestational anaemia resulting from malaria $[7,8]$. These and other adverse outcomes during pregnancy can be worse in areas where P. falciparum or Plasmodium vivax are endemic $[9,10]$. Pregnant women are, therefore, three times more at risk of dying due to malaria compared to non-pregnant women [11].

LLINs are an important preventive measure against malaria, however, they are used by one-fourth of the pregnant women in the world. Proper use of LLINs protects against malaria and transience from malaria [12-17]. Moreover, the frequency of malaria cases can be reduced to half among pregnant women only by using LLINs [14]. Use of LLINs may reduce reproduction number $R$ (meant population where all individuals are susceptible to infection) of malarial parasites, which means if three quarters of the population uses LLINs, it could effectively eliminate malaria in the community [18]. Hence, proper use of LLINs in high endemic areas helps reduce malaria vector transmission and burden of malaria in the community [19]. LLINs act as a physical barrier and kill the mosquitoes offering a definitive shield against malaria [20]. Mass distribution of LLINs is a proven and cost-effective intervention to prevent malaria. Moreover, adequate knowledge and use of LLINs is considered an important factor against prevention of malaria $[12,21]$.
However, the challenges is that a mere availability of LLINs may not necessarily lead to their use, unless interventions focus upon knowledge that addresses the perceptions, misconceptions and promotes positive behaviours about the prevention of malaria [22]. The usefulness of LLIN dissemination in the community as an intervention is one of the strategies that can be complemented with its proper use by imparting knowledge, maintenance, and regular replacement. Hence, the World Health Organization (WHO) recommends assessing and evaluating the proper knowledge and use of LLINs to improve its use in the vulnerable communities facing a high burden of malaria. There is need to study factors capable of influencing knowledge and use of LLINs especially by vulnerable population groups like pregnant women in remote areas of Pakistan. This evaluation can provide useful insights about the gap between distribution of LLINs and their uptake by the communities. However, scarcely any previous studies have explored the factors that affect knowledge and use of LLINs among pregnant women in Pakistan. This study is aimed to determine the independent factors predicting the knowledge and use of LLINs to prevent malaria in pregnant women in rural Pakistan.

\section{Methods}

This study was part of a larger interventional study employing quasi-experimental before and after design where baseline data were analysed before a health education intervention for malaria prevention among pregnant women of a rural district in the province of Sindh in Pakistan. The detailed methodology is published elsewhere [12]. Briefly, a sample of 200 pregnant women was recruited for data collection based on the sample size calculation with $80 \%$ power and alpha error of 0.50 to determine $30 \%$ difference. A multistage cluster random sampling technique was used to select study participants. First, union councils (smaller administrative areas in Pakistan) were selected from a list of 44 union councils in the district (primary sampling unit). Next, two union councils (Pathapur and Veeravah) were randomly selected for this study. In each union council, 10 villages were selected from a list of villages through simple random sampling method (secondary sampling unit), and in each village 10 pregnant women were selected through simple random sampling method from the list provided by the local Lady Health Workers. Pregnant women and mothers of children up to 6 months of age were part of the study who were interviewed at their homes. The women who were ill and did not belong to the study area at the time of the data collection were excluded. A validated and reliable Malaria Indicator Survey questionnaires developed by Roll Back Malaria Partnership 
Monitoring and Evaluation Reference Group was used in this study $[3,23]$.

Descriptive statistics were calculated for each knowledge and use of LLINs item. In order to test hypothesis that demographic/Independent variables (e.g., level of education, type of household, source of water) will predict knowledge and usage of LLINs among pregnant women, Multiple Linear Regression was used to predict knowledge about malaria and use of LLINS among pregnant women after controlling for age, level of education, mobile use, type of household, source of drinking water, type of latrine, mode of sewage, antenatal checkup, counselling about precaution against malaria during pregnancy, death of a newborn, malaria during previous and current pregnancy.

\section{Ethical approval}

The study was approved by the Institutional Ethics Review Board of the Health Services Academy, Islamabad, Pakistan (F.No.7/82/2017-IERB). Written and informed consent was received from the participants before data collection.

\section{Results}

The age of the women was from 18 to 45 years. Only (21\%) women had completed ten years of school education and most $(72.5 \%)$ were uneducated. The majority (77\%) of the women were married at or earlier than 18 years of age. More than half $(58.5 \%)$ of the women had from 3 to 4 children. Most (80.5\%) women lived in mud houses consisting of three to four rooms, $62.5 \%$ did not own a mobile phone and $60 \%$ did not have an improved source of drinking water, $38 \%$ participants used open latrine, and $48.5 \%$ had open sewage drainage system in their households. Most (91.5\%) of the women had monthly income from 5000 to 10,000 Pakistani rupees $(\mathrm{USD}=33-65)$. Most (92\%) of the women had history of making at least one antenatal care visit during their pregnancy and only $29.5 \%$ women received counseling on malaria during their antenatal care visit. Only a fifth of the women had history of malaria during their last pregnancy and only $(1.5 \%)$ reported malaria during their current pregnancy (Table 1).

Multiple linear regression was used to predict knowledge about malaria among pregnant women based on the independent variables (e.g., age, level of education). A significant regression equation was found [ $F$ (12, $187)=5.779 ; p<0.001]$ with an $R^{2}$ i.e., amount of variance explained by independent variables was 0.271 or $27 \%$. However, it can be seen that out of 12 independent variables (IVs), only five variables added statistically significant difference to the prediction of knowledge, i.e., level of education, us of mobile phone, type of latrine, malaria
Table 1 Baseline characteristics and information about malaria among pregnant women $(n=200)$

\begin{tabular}{|c|c|c|}
\hline Variables & Frequency & Percentage \\
\hline \multicolumn{3}{|l|}{ Age } \\
\hline$<20$ years & 17 & 8.5 \\
\hline $20-25$ & 44 & 22 \\
\hline 26 and above & 139 & 69.5 \\
\hline \multicolumn{3}{|l|}{ Education } \\
\hline Uneducated & 145 & 72.5 \\
\hline 10 year & 42 & 21 \\
\hline 12 years and above & 13 & 6.5 \\
\hline \multicolumn{3}{|c|}{ Number of living children } \\
\hline $1-2$ & 27 & 13.5 \\
\hline $3-4$ & 117 & 58.5 \\
\hline 5 and above & 56 & 28 \\
\hline \multicolumn{3}{|l|}{ Death of a newborn } \\
\hline Yes & 44 & 22 \\
\hline No & 156 & 78 \\
\hline \multicolumn{3}{|l|}{ Age at marriage } \\
\hline 18 and below & 154 & 77 \\
\hline 19 and above & 46 & 23 \\
\hline \multicolumn{3}{|l|}{ Type of household } \\
\hline Mud house & 161 & 80.5 \\
\hline Brick house & 39 & 19.5 \\
\hline \multicolumn{3}{|l|}{ Number of rooms } \\
\hline $1-2$ & 51 & 25.5 \\
\hline $3-4$ & 149 & 74.5 \\
\hline \multicolumn{3}{|l|}{ Owns a mobile phone } \\
\hline Yes & 75 & 37.5 \\
\hline No & 125 & 62.5 \\
\hline \multicolumn{3}{|l|}{ Source of drinking water } \\
\hline A well outside home & 120 & 60 \\
\hline A well inside home & 49 & 24.5 \\
\hline Handpump & 31 & 15.5 \\
\hline \multicolumn{3}{|l|}{ Type of latrine } \\
\hline Open & 76 & 38 \\
\hline Pit Latrine & 123 & 61.5 \\
\hline Flush & 1 & 0.5 \\
\hline \multicolumn{3}{|c|}{ Mode of sewage drainage in house } \\
\hline Open sewers & 97 & 48.5 \\
\hline Underground sewers & 27 & 13.5 \\
\hline In open pond & 49 & 24.5 \\
\hline No sewerage system & 27 & 13.5 \\
\hline \multicolumn{3}{|l|}{ Income (PKR) } \\
\hline $5000-10,000$ & 183 & 91.5 \\
\hline $11,000-20,000$ & 17 & 8.5 \\
\hline \multicolumn{3}{|l|}{ Antenatal checkup } \\
\hline Yes & 184 & 92 \\
\hline No & 16 & 8 \\
\hline \multicolumn{3}{|l|}{ No. of antenatal visits } \\
\hline 1 & 15 & 7.5 \\
\hline 2 & 95 & 47.5 \\
\hline
\end{tabular}


Table 1 (continued)

\begin{tabular}{lcl}
\hline Variables & Frequency & Percentage \\
\hline 3 & 38 & 19 \\
4 & 36 & 18 \\
Did not answer & 16 & 8 \\
ANC counseling on malaria & & \\
Yes & 59 & 29.5 \\
No & 141 & 70.5 \\
Malaria during any previous pregnancy & & \\
Yes & 42 & 21 \\
No & 158 & 79 \\
Malaria during the current pregnancy & & \\
Yes & 3 & 1.5 \\
No & 197 & 98.5 \\
\hline
\end{tabular}

during previous pregnancy and newborn death. Furthermore, it can be inferred that the type of latrine was the most significant $(\beta=0.285, p<0.001)$ determinant of knowledge about malaria among pregnant women followed by the death of a newborn $(\beta=0.271, \mathrm{p}<0.001)$ as shown in (Table 2).

Similarly, multiple linear regression was also calculated to explore the most significant independent variables that can predict usage of LLINs among pregnant women. As shown in Table 3, a significant regression equation was found $[\mathrm{F}(12,187)=4.579 ; \mathrm{p}<0.001]$ with an $\mathrm{R}^{2}$ i.e. amount of variance explained by independent variables is 0.178 or $19 \%$. Additionally, as with Knowledge, same independent variables had variance, which was significant $(\mathrm{p}<0.05)$ to predict usage of LLINs. Furthermore, use of mobile phone was most significant $(\beta=0.247$, $\mathrm{p}<0.001)$ predictor of usage of LLINs among pregnant women followed by death of a newborn $(\beta=0.232$, $\mathrm{p}<0.05)$.

\section{Discussion}

Maternal education, type of latrine, use of mobile phone, malaria during previous pregnancy and newborn death were significant predictors of knowledge and use of LLINs among pregnant women in this study. This study was conducted in the rural area of Tharparkar, a high endemic area with significant malaria infection, high poverty, illiteracy and poor overall infrastructure development status. Studies have also supported the findings and shows a clear link between maternal education and poverty, and incidence of malaria in pregnant women and their newborns $[22,24]$. The use of LLINs has been shown to be higher in educated mothers and those receiving regular antenatal care and counselling [12, 25]. A study from Nigeria showed that maternal education can effectively prevent malaria in rural communities [26]. Female education is crucial to the prevention of malaria in pregnancy [27]. Successful Health education campaigns can encourage the use of LLINs [28]. Educational interventions can also improve knowledge about malaria leading to a higher use of LLINs [15]. Evidence shows that educational interventions can improve the use of LLINs by $30 \%$ in rural communities [29].

Type of latrine used by the community was another strong factor determining both knowledge and use of LLINS among pregnant women in this study. However,

Table 2 Multiple linear regression analysis to predict Knowledge of pregnant women regarding malaria

\begin{tabular}{|c|c|c|c|c|c|c|c|c|}
\hline Variables & $\mathbf{R}$ & $\mathrm{R}^{2}$ & $\Delta R^{2}$ & $\mathrm{~B}$ & SE & $\beta$ & $\mathbf{t}$ & Sig(p) \\
\hline & 0.520 & 0.271 & 0.224 & & & & & $0.014^{*}$ \\
\hline Age & & & & 0.159 & 0.234 & 0.049 & 0.680 & 0.497 \\
\hline Level of education & & & & -0.647 & 0.177 & -0.262 & -3.648 & $0.000^{* *}$ \\
\hline Mobile phone use & & & & 0.973 & 0.403 & 0.166 & 2.416 & $0.017^{*}$ \\
\hline Type of household & & & & -1.037 & 0.719 & -0.151 & -1.442 & 0.151 \\
\hline Source of drinking water & & & & -0.066 & 0.434 & -0.017 & -0.152 & 0.879 \\
\hline Type of latrine & & & & 1.635 & 0.487 & 0.285 & 3.357 & $0.001 * *$ \\
\hline Mode of sewage & & & & 0.126 & 0.246 & 0.050 & 0.512 & 0.609 \\
\hline Antenatal check-up & & & & -0.797 & 0.747 & -0.076 & -1.067 & 0.287 \\
\hline $\begin{array}{l}\text { Counselling about precaution against } \\
\text { malaria during pregnancy }\end{array}$ & & & & 0.071 & 0.595 & 0.011 & 0.119 & 0.906 \\
\hline Death of new born & & & & 1.854 & 0.575 & 0.271 & 3.225 & $0.001 * *$ \\
\hline Malaria during previous pregnancy & & & & -1.389 & 0.497 & -0.208 & -2.793 & $0.006^{* *}$ \\
\hline Malaria during current pregnancy & & & & 1.476 & 1.549 & 0.063 & 0.953 & 0.342 \\
\hline
\end{tabular}

$R^{2}$ amount of variance explained by IVs, $\Delta R^{2}$ additional variance in DV, $B$ unstandardized coefficient, SEStandard Error, $\beta$ Standardized coefficient, $t$ estimated coefficient ${ }^{*} \mathrm{p}<0.05,{ }^{* *} \mathrm{p}<0.01$ 
Table 3 Multiple Linear Regression analysis to analysis to predict Use of LLINs among pregnant women

\begin{tabular}{|c|c|c|c|c|c|c|c|c|}
\hline Variables & $\mathbf{R}$ & $R^{2}$ & $\Delta \mathrm{R}^{2}$ & B & SE & $\beta$ & $t$ & Sig(p) \\
\hline & 0.477 & 0.227 & 0.178 & & & & & $0.001^{* *}$ \\
\hline Age & & & & 0.082 & 0.184 & 0.033 & 0.445 & 0.657 \\
\hline Level of education & & & & -0.381 & 0.138 & -0.202 & -2.735 & $0.007^{* *}$ \\
\hline Mobile phone use & & & & 1.102 & 0.316 & 0.247 & 3.488 & $0.001^{* *}$ \\
\hline Type of household & & & & -0.739 & 0.564 & -0.141 & -1.311 & 0.191 \\
\hline Source of drinking water & & & & 0.183 & 0.340 & 0.063 & 0.537 & 0.592 \\
\hline Type of latrine & & & & 0.904 & 0.382 & 0.207 & 2.367 & $0.019^{*}$ \\
\hline Mode of sewage & & & & -0.088 & 0.193 & -0.046 & -0.454 & 0.651 \\
\hline Antenatal check-up & & & & -0.630 & 0.586 & -0.079 & -1.076 & 0.283 \\
\hline $\begin{array}{l}\text { Counselling about precaution against } \\
\text { malaria during pregnancy }\end{array}$ & & & & 0.168 & 0.467 & 0.036 & 0.361 & 0.719 \\
\hline Death of a newborn & & & & 1.210 & 0.451 & 0.232 & 2.683 & $0.008^{* *}$ \\
\hline Malaria during previous pregnancy & & & & -0.983 & 0.390 & -0.193 & -2.521 & $0.013^{*}$ \\
\hline Malaria during current pregnancy & & & & -0.345 & 1.215 & -0.019 & -0.284 & 0.777 \\
\hline
\end{tabular}

${ }^{*} \mathrm{p}<0.05,{ }^{* *} \mathrm{p}<0.01$

$R^{2}$ amount of variance explained by IVs, $\Delta R^{2}$ additional variance in DV, B unstandardized coefficient, SE Standard Error, $\beta$ Standardized coefficient, $t$ estimated coefficient

most of the study population was using the pit latrine with open drainage system at the time of this study. This type of latrine use can lead to problems like leakage of water from wastewater drain, which can create suitable environment and breeding ground for the growth of mosquitoes leading to a high incidence of malaria in these communities. The findings of this study are supported by the existing evidence showing that poor sanitation is directly linked with high incidence of parasitic infections and vector borne diseases including malaria $[30,31]$. Improved toilet use, like the use of flush toilet with piped water, is linked with a reduction in the incidence of malaria [32].

Mobile phone use among the pregnant women is found positive predictor for knowledge and use of LLINs. This finding is supported by an experimental study proved that the mobile phone short messages are an effective intervention to prevent malaria [33]. Mobile health interventions are strongly associated on health outcomes if the messages are constructed to affect people's behavior. Moreover, malaria treatment adherence and awareness may be increased through regular mobile phone messages in malaria patients. The findings of present study are consistent with these studies [34].

Malaria during previous pregnancy and newborn death were strong predictors of the knowledge and use of LLINs among pregnant women in this study. This could be because of the knowledge gained about the transmission of malaria during previous pregnancy resulting in the death of a newborn. This finding is supported by a longitudinal survey that showed that the newborns are at high risk of death and observed a significant reduction in mean birth weight in babies of women with malaria during pregnancy. Malaria during pregnancy was a predictor of knowledge and use of LLINs, and it is a known risk of adverse pregnancy outcomes like miscarriage, preterm birth, stillbirth, and low birth weight leading to high infant mortality [5, 35]. The finding of previous malaria infection strongly underscores the need for preventive efforts during malaria. The newborn mortality and premature birth are a known consequence of malaria in pregnancy [36]. Conditions like low birth weight in turn cause intrauterine growth retardation and preterm birth, which are leading causes of newborn mortality in low- and middle-income countries [7, 37]. These findings are reported from the baseline data analysed before the health education intervention for malaria prevention among pregnant women of the same rural area published elsewhere [12]. Based on the trends shown in this baseline study, comparable results are expected if the intervention is implemented at a larger scale. Since the respondents were selected from separate UCs, it could be assumed that due to a sufficient distance between the two areas, any possibilities of contamination were minimum. Sample selection by simple random sampling method was a strength of this study. Another strength of this study was that the use of multiple linear regression analysis has predicted the factors, which are validated by the existing knowledge and use of LLINs for the prevention of malaria.

This study cannot be generalized to the whole population in Pakistan the sample was selected from only one 
district. Moreover, limited funds and time constraints were the major limitations of this study. Further evidence may be generated through community trials to test the effectiveness of these factors/ predictors and also understand the host-seeking behaviour and response of mosquitoes to LLINs.

\section{Conclusions}

The education level, mobile phone usage, type of latrine, death of a newborn and malaria during previous pregnancy were most significant predictors of knowledge and use of LLINs among pregnant women of rural Pakistan. Therefore, there is a need to scale-up programmes, which aim at creating awareness regarding malaria among pregnant women. This analysis may help streamline interventions to enhance uptake of LLINs (along with intermittent preventive treatment in pregnancy) [38]. It is recommended that health policy makers may focus on female education and start awareness programmes on malaria prevention through regular mobile phone messages. Mobile phone technology could be used as a strategy for controlling malaria in high-risk group, i.e., pregnant women.

\section{Abbreviations}

EMRO: Eastern Mediterranean regional Office; UC: Union council; LLINs: Longlasting insecticidal nets; LHW: Lady Health Worker; BHU: Basic health unit; TDR: Tropical disease research; WHO: World Health Organization.

\section{Acknowledgements}

We acknowledge the support by Ratchadapisek Somphot Fund for Postdoctoral Fellowship, Chulalongkorn University Thailand and Tropical disease research small grant scheme for implementation research in infectious diseases by WHO/EMRO.

\section{Authors' contributions}

RK conceptualized this study; MF analyse the data and ML drafted the manuscript, JA revised the paper; RS supervised this research and finalized the manuscript. All authors read and approved the final manuscript.

\section{Funding}

This research was supported by TDR-SGS grant number (18-31) WHO/EMRO/ TDR.

\section{Availability of data and materials}

The datasets used and/or analysed during the current study are available from the corresponding author on reasonable request.

\section{Declarations}

\section{Ethics approval and consent to participate}

All respondents provided written informed consent obtained before to include in this study and ethical approval were taken from Institutional Review Board of Health Services Academy Pakistan.

\section{Consent for publication}

Not applicable.

\section{Competing interests}

The authors declare that they have no competing interests.

\section{Author details}

${ }^{1}$ Health Services Academy, Ministry of National Health Services Regulation and Coordination, Government of Pakistan, Islamabad, Pakistan. ${ }^{2}$ Department of Family and Community Medicine, College of Medicine and Medical Sciences, Arabian Gulf University, Manama, Bahrain. ${ }^{3}$ College of Public Health Sciences, Chulalongkorn University, Bangkok, Thailand.

Received: 19 May 2021 Accepted: 15 August 2021

Published online: 23 August 2021

\section{References}

1. WHO. World malaria report. Geneva: World Health Organization; 2019.

2. Qureshi NA, Fatima H, Afzal M, Khattak AA, Nawaz MA. Occurrence and seasonal variation of human Plasmodium infection in Punjab Province, Pakistan. BMC Infect Dis. 2019;1 9:935.

3. Pakistan Malaria Annual Report. Directorate of Malaria Control, Ministry of National Health Services Regulation and Coordination Government of Pakistan, Islamabad. 2019.

4. Bhatti MA, Azharuddin M, Bhatti S, Islam M, Khan MA. Malaria and pregnancy: the perspective in Pakistan. J Pak Med Assoc. 2007;57:15-8.

5. Dombrowski JG, de Souza RM, Silva NRM, Barateiro A, Epiphanio S, Goncalves $L A$, et al. Malaria during pregnancy and newborn outcome in an unstable transmission area in Brazil: a population-based record linkage study. PLoS ONE. 2018;13:e0199415.

6. Huynh BT, Cottrell G, Cot M, Briand V. Burden of malaria in early pregnancy: a neglected problem? Clin Infect Dis. 2015;60:598-604.

7. Ishaque S, Yakoob MY, Imdad A, Goldenberg RL, Eisele TP, Bhutta ZA. Effectiveness of interventions to screen and manage infections during pregnancy on reducing stillbirths: a review. BMC Public Health. 2011;11(Suppl 3):3.

8. Romero M, Leiba E, Carrion-Nessi FS, Freitas-De Nobrega DC, Kaid-Bay $\mathrm{S}$, Gamardo AF, et al. Malaria in pregnancy complications in Southern Venezuela. Malar J. 2021;20:186.

9. Dombrowski JG, Barateiro A, Peixoto EPM, Barros A, Souza RM, Clark TG, et al. Adverse pregnancy outcomes are associated with Plasmodium vivax malaria in a prospective cohort of women from the Brazilian Amazon. PLoS Negl Trop Dis. 2021;15:e0009390.

10. Dosoo DK, Chandramohan D, Atibilla D, Oppong FB, Ankrah L, Kayan K, et al. Epidemiology of malaria among pregnant women during their first antenatal clinic visit in the middle belt of Ghana: a cross sectional study. Malar J. 2020;19:381.

11. Fana SA, Bunza MD, Anka SA, Imam AU, Nataala SU. Prevalence and risk factors associated with malaria infection among pregnant women in a semi-urban community of north-western Nigeria. Infect Dis Poverty. 2015;4:24.

12. Kumar R, Farzeen M, Hafeez A, Achakzai BK, Vankwani M, Lal M, et al. Effectiveness of a health education intervention on the use of longlasting insecticidal nets for the prevention of malaria in pregnant women of Pakistan: a quasi-experimental study. Malar J. 2020;19:232.

13. Whidden CE, Premaratne RG, Jayanetti SR, Fernando SD. Patterns and predictive factors of long-lasting insecticidal net usage in a previously high malaria endemic area in Sri Lanka: a cross-sectional survey. Trans R Soc Trop Med Hyg. 2015;109:553-62.

14. Gamble C, Ekwaru PJ, Garner P, ter Kuile FO. Insecticide-treated nets for the prevention of malaria in pregnancy: a systematic review of randomised controlled trials. PLoS Med. 2007;4:e107.

15. Deribew A, Birhanu Z, Sena L, Dejene T, Reda AA, Sudhakar M, et al. The effect of household heads training on long-lasting insecticide-treated bed nets utilization: a cluster randomized controlled trial in Ethiopia. Malar J. 2012;11:99.

16. Hambisa MT, Debela T, Dessie Y, Gobena T. Long lasting insecticidal net use and its associated factors in Limmu Seka District, South West Ethiopia. BMC Public Health. 2018;18:124.

17. Hounkonnou C, Djenontin A, Egbinola S, Houngbegnon P, Bouraima A, Soares $C$, et al. Impact of the use and efficacy of long lasting insecticidal net on malaria infection during the first trimester of pregnancy - a pre-conceptional cohort study in southern Benin. BMC Public Health. 2018;18:683. 
18. Agusto FB, Del Valle SY, Blayneh KW, Ngonghala CN, Goncalves MJ, Li $\mathrm{N}$, et al. The impact of bed-net use on malaria prevalence. J Theor Biol. 2013;320:58-65.

19. ter Kuile FO, Terlouw DJ, Phillips-Howard PA, Hawley WA, Friedman JF, Kariuki SK, et al. Reduction of malaria during pregnancy by permethrintreated bed nets in an area of intense perennial malaria transmission in western Kenya. Am J Trop Med Hyg. 2003;68(4 Suppl):50-60.

20. Killeen GF, Smith TA, Ferguson HM, Mshinda H, Abdulla S, Lengeler $C$, et al. Preventing childhood malaria in Africa by protecting adults from mosquitoes with insecticide-treated nets. PLoS Med. 2007;4:e229.

21. Balami AD, Said SM, Zulkefli NAM, Bachok N, Audu B. Effects of a health educational intervention on malaria knowledge, motivation, and behavioural skills: a randomized controlled trial. Malar J. 2019:18:41.

22. Ankomah A, Adebayo SB, Arogundade ED, Anyanti J, Nwokolo E, Ladipo $\mathrm{O}$, et al. Determinants of insecticide-treated net ownership and utilization among pregnant women in Nigeria. BMC Public Health. 2012;12:105.

23. Wanzira H, Eganyu T, Mulebeke R, Bukenya F, Echodu D, Adoke Y. Long lasting insecticidal bed nets ownership, access and use in a high malaria transmission setting before and after a mass distribution campaign in Uganda. PLoS ONE. 2018:13:e0191191.

24. Njau JD, Stephenson R, Menon MP, Kachur SP, McFarland DA. Investigating the important correlates of maternal education and childhood malaria infections. Am J Trop Med Hyg. 2014;91:509-19.

25. Soleimani-Ahmadi M, Vatandoost H, Zare M, Alizadeh A, Salehi M. Community knowledge and practices regarding malaria and long-lasting insecticidal nets during malaria elimination programme in an endemic area in Iran. Malar J. 2014;13:511

26. Amoran OE. Impact of health education intervention on malaria prevention practices among nursing mothers in rural communities in Nigeria. Niger Med J. 2013;54:115-22.

27. Thuilliez J, Sissoko MS, Toure OB, Kamate P, Berthelemy JC, Doumbo OK. Malaria and primary education in Mali: a longitudinal study in the village of Doneguebougou. Soc Sci Med. 2010;71:324-34.

28. Ahmed SM, Hossain S, Kabir MM, Roy S. Free distribution of insecticidal bed nets improves possession and preferential use by households and is equitable: findings from two cross-sectional surveys in thirteen malaria endemic districts of Bangladesh. Malar J. 2011;10:357.

29. Chirdan OO, Zoakah Al, Ejembi CL. Impact of health education on home treatment and prevention of malaria in Jengre, North Central Nigeria. Ann Afr Med. 2008;7:112-9.

30. Monteiro TH, Chaves Tdo S, Matos HJ, Sofffiatti NF, Guimaraes RJ, Guimaraes $\mathrm{LH}$, et al. Basic sanitation, socioeconomic conditions, and degree of risk for the presence and maintenance of malaria in a low-transmission area in the Brazilian Amazon. Rev Soc Bras Med Trop. 2015;48:573-9.

31. Aberese-Ako M, Magnussen P, Ampofo GD, Tagbor H. Health system, socio-cultural, economic, environmental and individual factors influencing bed net use in the prevention of malaria in pregnancy in two Ghanaian regions. Malar J. 2019;18:363.

32. Yang D, He Y, Wu B, Deng Y, Li M, Yang Q, et al. Drinking water and sanitation conditions are associated with the risk of malaria among children under five years old in sub-Saharan Africa: a logistic regression model analysis of national survey data. J Adv Res. 2020;21:1-13.

33. Mohammed A, Acheampong PR, Otupiri E, Osei FA, Larson-Reindorf R, Owusu-Dabo E. Mobile phone short message service (SMS) as a malaria control tool: a quasi-experimental study. BMC Public Health. 2019;19:1193.

34. Talisuna AO, Zurovac D, Githinji S, Oburu A, Malinga J, Nyandigisi A, et al. Efficacy of mobile phone short message service (SMS) reminders on malaria treatment adherence and day 3 post-treatment reviews (SMSRES-MAL) in Kenya: a study protocol. J Clin Trials. 2019:5:217.

35. Chua CLL, Hasang W, Rogerson SJ, Teo A. Poor birth outcomes in malaria in pregnancy: recent insights into mechanisms and prevention approaches. Front Immunol. 2021;12:621382.

36. Rogerson SJ. Malaria in pregnancy and the newborn. Adv Exp Med Biol. 2010;659:139-52.

37. Alvarez-Larrotta C, Carmona-Fonseca J. [Consequences of gestational malaria infection in the immune function and immunomodulation of mother and newborn](in Spanish). Rev Chilena Infectol. 2019;36:341-52.

38. Wafula ST, Mendoza H, Nalugya A, Musoke D, Waiswa P. Determinants of uptake of malaria preventive interventions among pregnant women in eastern Uganda. Malar J. 2021;20:5.

\section{Publisher's Note}

Springer Nature remains neutral with regard to jurisdictional claims in published maps and institutional affiliations.
Ready to submit your research? Choose BMC and benefit from:

- fast, convenient online submission

- thorough peer review by experienced researchers in your field

- rapid publication on acceptance

- support for research data, including large and complex data types

- gold Open Access which fosters wider collaboration and increased citations

- maximum visibility for your research: over $100 \mathrm{M}$ website views per year

At BMC, research is always in progress.

Learn more biomedcentral.com/submissions 